\title{
Compliance Amongst Warfarin Users Diagnosed Non-valvular Atrial Fibrillation are We Aware: Prospective Survey
}

\author{
Hashem Mansour $^{1 *}$, Rafat Lubbad ${ }^{2}$, Hasan Aboobaid $^{3}$, Khamis Issi $^{4}$ \\ ${ }^{1}$ Clinical Pharmacy, Palestine University and Indonesian Hospital, Gaza, Palestinian Territory; ${ }^{2}$ Internal Medicine, Indonesian \\ Hospital, Gaza, Palestinian Territory; ${ }^{3}$ Public Health, Indonesian Hospital, Gaza, Palestinian Territory; Internal Medicine, Islamic \\ University Gaza, Gaza, Palestinian Territory
}

\begin{abstract}
Introduction: Vitamin k antagonists are the most commonly prescribed anticoagulation among non-valvular atrial fibrillation patients. It is indicated for stroke prevention in this group of patients. The aim of this study is to assess patient compliance among NVAF warfarin users.

Method: The study designed as prospective study, conducted in the medical department in Indonesian and Shifa hospital- Palestine. We included patients undergoing oral anticoagulation with VKA diagnosed with NVAF with diabetes, cardiovascular disease aged between 20-85 years old, otherwise were excluded. The laboratory data include the INR, creatinine clearance, random blood sugar, systolic and diastolic blood pressure, liver chemistry extracted from patient file.

Analysis: Continuous data are presented as the mean \pm standard deviation, and the categoric variables were presented as percentage. To find the relationship between quantitative variables we used binary univariate analysis statistically significant results were considered at a two-tailed p-value <0.05. Data were analyzed using SPSS version 20 software.

Finding: The total number was 100 patients, 50\% males and the remain females. The results show that $43 \%$ of the patients know the risk of the drug while 39\% know about the benefit. Only 58\% of patients are within the therapeutic INR and $66 \%$ do not follow regular INR monitoring. There was $28 \%$ of patients are not in contact with any health care providers for drug monitoring. The results also show that $21 \%$ of patients do not follow their daily dose and 36\% complain of hemorrhage. The results clarify that there exists a positive relationship between a creatinine, diastolic Bp, systolic Bp and INR Since p-value <0.05.

Interpretation: The finding of this study shows that most of our patients' unaware warfarin, so we recommend construction of warfarin clinic for this group of patients for regular follow up with education program with qualified health care provider.
\end{abstract}

Keywords: Warfarin; Anticoagulation; Bleeding

\section{INTRODUCTION}

Vitamin $\mathrm{k}$ antagonists are the most commonly prescribed drugs for anticoagulation. The prevalence of AF ranged between $0.5 \%$ and $1 \%$ in the general population [1,2]. The dose of the drug depends on the international normalized ratio (INR) for those with NVAF the normal range is 2-3 [3]. The drug mainly indicated for valvular heart disease, nonvalvular atrial fibrillation (NVAF), venous thromboembolism (VTE) in addition to other conditions and the INR therapeutic target depends on each condition separately [4-6]. Several studies demonstrated that the drug is significantly underused in clinical situations [1].

${ }^{*}$ Correspondence to: Dr. Hashem Mansour, Clinical Pharmacy, Palestine University and Indonesian Hospital, Gaza, Palestinian Territory, Tel: 009722472176 / 00972599716346 ; E-mail: hashemmansour1@yahoo.com

Received: March 04, 2019; Accepted: March: 20, 2019; Published: March 29, 2019

Citation: Mansour H, Lubbad R, Aboobaid H, Issi K (2019) Compliance amongst warfarin users diagnosed non-valvular atrial fibrillation are we aware; prospective survey. Cardiovasc Pharm Open Access. 8: 252. doi: 10.35248/2329-6607.19.8.252

Copyright: ( 2019 Mansour H, et al. This is an open access article distributed under the terms of the Creative Commons Attribution License, which permits unrestricted use, distribution, and reproduction in any medium, provided the original work is properly cited. 
Ineffective control of warfarin therapy associated with increased risk of hemorrhage, with intracranial bleeding being the most dreadful form [7-9]. Close monitoring of INR associated with reduced risk of bleeding, re- thrombosis and better outcome [10-12]. The variability in INR is an indicator to assess the intensity of warfarin treatment [13]. Co-administration of warfarin with some drugs as aspirin or clopidogrel associated with increases the risk of hemorrhage $[14,15]$. The risk factors associated with risk increased probability for intracranial bleeding were renal failure, advanced age, hypertension, prior stroke and male sex [16-18]. Prior knowledge and patient awareness about warfarin has been associated with a decreased risk of bleeding and achieving the goal of therapy [19,20]. Standardizing the educational content, and delivering the content more efficiently is necessary to improve the quality of anticoagulation with warfarin [21,22]. Past studies suggest that patient education may be associated with better clinical outcomes, doubts remain about the effectiveness of patient education strategies [23-25]. Patient education was found to improve knowledge relating to patient safety in a durable manner, hence regular counseling with timely assessment of their understanding is necessary [26,27]. More than half of patients receiving VKAs are admitted with an INR falling outside the therapeutic range, irrespective of the bleeding or embolic risk. Identifying patient groups with the lowest time interval spent in the therapeutic range could help educating patients and improve efficiently without compromising patient's safety, more over improvement in the quality of life of patients receiving warfarin therapy [28-31]. This study is the first study concerning warfarin among non-valvular AF (NVAF) patients in Gaza Strip according to the researcher's knowledge.

The aim of this study is to assess patient compliance among warfarin users and establish patient awareness on the therapeutic effectiveness in the internal medicine and cardiology department, with the hypothesis that this can help understanding and predict the factors associated with nonadherence.

\section{METHODOLOGY}

\section{Study population}

This is a prospective study which was conducted during the period $(1 / 1 / 2017-1 / 8 / 2018)$ in the internal medical and cardiac department of the Indonesian hospitals in Gaza. We included consecutive patients undergoing oral anticoagulation (OACT) with VKA agents due to non-valvular atrial fibrillation who agreed to participate to the study. The inclusion criteria were patients with NVAF with diabetes, cardiovascular disease or lone NVAF aged more than 20 years old and less than 80 years old. Patients with renal failure whether on dialysis or not, cancer, valvular heart disease, antiphospholipid syndrome, thrombophilia, patients on VKA of less than three months, patients on antiplatelets in addition to VKA, new oral anticoagulation (NOAC) or recurrent venous thromboembolism disease were excluded.

\section{Data collection}

For the purpose of data collection, we developed a questionnaire containing 17 questions. The questions were designed to assess patients' background, educational level, knowledge about the diagnosis for which OACT was prescribed, and general knowledge about OACT, as well as assessing their compliance with treatment and periodic INR testing. The preferred method of administering the questionnaire was with the help of clinical pharmacist via face to face interview, as this overcame barriers concerning literacy, visual impairment, or understanding of more technical questions. For each patient, the diagnosis of NVAF was confirmed by two cardiologists. The laboratory data and blood pressure were recorded at the start of the study. For each patient, we determined several variables to be included in the database: age, the INR, creatinine clearance, fasting blood sugar, systolic and diastolic blood pressure, liver enzymes and questions related to knowledge of the patient about the drug.

Table 1: Baseline characters of the cohort.

\begin{tabular}{|c|c|c|c|}
\hline Variable & & Frequency & percent \\
\hline \multirow[t]{2}{*}{ Gender } & Male & 53 & 53 \\
\hline & Female & 47 & 47 \\
\hline \multirow[t]{3}{*}{ Mean Age in Years } & $<50$ & 34 & 34 \\
\hline & $50-80$ & 57 & 57 \\
\hline & $>80$ & 9 & 9 \\
\hline \multirow[t]{5}{*}{ Co-Morbid Condition } & HTN & 30 & 43.5 \\
\hline & $\mathrm{DM}$ & 34 & 10.9 \\
\hline & Hypothyroidism & 9 & 2.2 \\
\hline & HTN and DM & 20 & 41.3 \\
\hline & $\begin{array}{l}\text { HTN, DM and } \\
\text { Hypothyroidism }\end{array}$ & 9 & 2.2 \\
\hline \multirow[t]{2}{*}{ Smoker } & Yes & 42 & 42 \\
\hline & No & 58 & 58 \\
\hline \multirow[t]{4}{*}{ Level of Education } & None & 25 & 25 \\
\hline & Less than 6 years & 35 & 35 \\
\hline & 6 yrs.-less than 12 & 30 & 30 \\
\hline & More than 12 yrs & 10 & 10 \\
\hline
\end{tabular}

\section{Statistical analysis}

Continuous data are expressed as the mean and standard deviation, and the categorical variables were presented as percentage. To determine the factors associated with poor 
adherence, including the patients' characteristics, clinical factors, univariate analysis was conducted using the chi-squared test or Fisher's exact test (as appropriate) for proportions and the twotailed t-test for mean. Statistically significant results were considered at a two-tailed $\mathrm{p}$-value $<0.05$.

All data were analyzed using Statistical Package for the Social Sciences version 20 software (IBM Corporation, Armonk, NY, USA). The study approved by HELSINKI committee- Gaza Strip- Palestine.

\section{RESULTS}

The study continued for 20 months with mean follow up of $14 \pm$ 6 months, started at $1 / 1 / 2017$ and ended at $1 / 8 / 2018$, the total number of participants were 100 patients. The patient characteristics, clinical information, and other information are listed in Table 1. Fifty-three (53\%) of the patients were male; the mean age was $55 \pm 5$ years. Forty-two $(42 \%)$ percent of the patients were current smokers. Approximately 30\% of the patients had hypertension, and $43 \%$ had diabetes mellitus, $9 \%$ had hypothyroidism and $29 \%$ had multiple comorbidities. The mean baseline data of chemistry and both systolic and diastolic blood pressure presented in (Tables 2 and 3).

Table 2: Baseline chemistry and blood pressure of the cohort.

\begin{tabular}{llll}
\hline Variable & & Mean & St Deviation \\
\hline Chemistry & Creatinine & 1 & 0.61 \\
\cline { 2 - 4 } & AST & 32 & 55.08 \\
\cline { 2 - 4 } & ALT & 28 & 25.19 \\
\cline { 2 - 4 } & platelets & 224 & 90.64 \\
\cline { 2 - 4 } & INR & 1.7 & 2.39 \\
\cline { 2 - 4 } & F.B.S & 138 & 87.03 \\
\hline Blood Pressure & Systolic & 120 & 16.52 \\
\cline { 2 - 4 } & Diastolic & 76 & 13.06 \\
\hline
\end{tabular}

ALT: Alanine Transaminase; BP: Blood Pressure; FBS: Fasting Blood Sugar, INR: international normalized ratio

\section{DISCUSSION}

Warfarin is one of the most commonly used drugs among nonvalvular atrial fibrillation patients for stroke prevention. It is considered one of the most dangerous drugs due to its complication. This drug needs continuous monitoring and follow up including patient education. In this study we try to evaluate the knowledge of our patients about the drug, so we conduct this pilot cross sectional survey. The result of this survey shows a big gap in the knowledge among the patients about warfarin. The results show that $43 \%$ of the patients have sufficient knowledge about the risk of the drug while just 39\% know about the benefit. Despite that $65 \%$ of patients follow their daily dose regularly only $58 \%$ of the cohort are within the therapeutic INR and $66 \%$ do not follow regular INR monitoring. This mean insufficient knowledge about warfarin due to incomplete or unclear information from the health care provider or due to low education level of the cohort (10\% level of education more than 12 years and 30\% 6-12-year education level) (Table 4).

Table 3: Patients knowledge about warfarin.

\begin{tabular}{|c|c|c|c|}
\hline Variable & & Frequency & Percent \\
\hline \multirow[t]{2}{*}{ Risk knowledge } & Yes & 43 & 43 \\
\hline & No & 57 & 57 \\
\hline \multirow[t]{2}{*}{ Benefit knowledge } & Yes & 39 & 39 \\
\hline & No & 61 & 61 \\
\hline \multirow[t]{5}{*}{ Daily dose } & 2.5 & 3 & 3 \\
\hline & 5 & 43 & 43 \\
\hline & 7.5 & 19 & 19 \\
\hline & 10 & 15 & 15 \\
\hline & 12.5 & 20 & 20 \\
\hline \multirow[t]{2}{*}{ Duration of therapy } & Less than one year & 49 & 49 \\
\hline & $\begin{array}{l}\text { More than one } \\
\text { year }\end{array}$ & 51 & 51 \\
\hline \multirow[t]{2}{*}{ Compliant with daily dose } & Yes & 65 & 65 \\
\hline & No & 35 & 35 \\
\hline \multirow[t]{2}{*}{ Within target INR } & Yes & 58 & 58 \\
\hline & No & 42 & 42 \\
\hline \multirow[t]{3}{*}{ INR frequency } & Once/week & 9 & 9 \\
\hline & Once /month & 25 & 25 \\
\hline & Not regular & 66 & 66 \\
\hline \multirow[t]{2}{*}{ Hemorrhage } & Yes & 34 & 34 \\
\hline & No & 66 & 66 \\
\hline \multirow[t]{3}{*}{ Type of hemorrhage } & Epistaxis & 16 & 44 \\
\hline & GI bleeding & 13 & 36 \\
\hline & $\begin{array}{l}\text { Macroscopic } \\
\text { Hematuria }\end{array}$ & 5 & 15 \\
\hline $\begin{array}{l}\text { Awareness of how to deal } \\
\text { with hemorrhage }\end{array}$ & Yes & 4 & 4 \\
\hline
\end{tabular}




\begin{tabular}{lll}
\hline No & 96 & 96 \\
\hline
\end{tabular}

There was $36 \%$ of patients are in contact with any specialist health care providers for monitoring of the drug, 36\% nonspecialist and $28 \%$ without any counselling, this decreases the adherence to the medication and increase the risk of adverse effects. The results also show that $21 \%$ of patients do not follow their daily dose and 34\% complain of different degrees of hemorrhagic episodes but none of them mention hospital admission, only $4 \%$ are aware of how to deal with this complication. The most common form of hemorrhage was epistaxis $44 \%$ and no CNS hemorrhage was observed.

Table 4: Who adjust your ACT dosage after the INR analysis?

\begin{tabular}{lll}
\hline $\begin{array}{l}\text { Who adjust your ACT dosage after } \\
\text { the INR analysis? }\end{array}$ & Frequency & Percent \\
\hline Specialist & 36 & 36 \\
\hline Physician & 26 & 26 \\
\hline Pharmacist & 10 & 10 \\
\hline No one & 28 & 28 \\
\hline Total & 100 & 100 \\
\hline
\end{tabular}

There was $36 \%$ complain of gastrointestinal hemorrhage which considered the second form of serious bleeding after CNS hemorrhage, since it requires hospital admission and close follow up and may lead to drug withdrawal or shift to other types of anticoagulants. Several factors increase the risk of gastrointestinal bleeding such low education level, older age, poor adherence, comorbid condition as this result in polypharmacy and more drug interactions.

Table 5: Relationship between variables and INR values above or below therapeutic range.

\section{INR}

\begin{tabular}{lll}
\hline & $\begin{array}{l}\text { Correlation } \\
\text { Coefficient }\end{array}$ & P-value \\
\hline Creatinine & 0.276 & 0.031 \\
\hline ALT & 0.032 & 0.869 \\
\hline Platelets & 0.08 & 0.567 \\
\hline F.B.S & -0.001 & 0.993 \\
\hline BP (Systolic) & -0.307 & 0.05 \\
\hline BP (diastolic) & -0.306 & 0.049 \\
\hline Daily dose & 0.041 & 0.748 \\
\hline
\end{tabular}

ALT: Alanine Transaminase; BP: Blood Pressure; FBS: Fasting Blood Sugar

These findings are consistent with $42 \%$ of patients away from the therapeutic range and this increases the risk of hemorrhage or stroke $(7-9,14,15,28-31)$. The daily dose was not strong factor for bleeding, may be other factors like drug interactions or food interactions which might play a major role. Our findings consistent with other studies which show poor adherence to warfarin in NVAF patients. The results clarify that there exists a positive relationship between a creatinine, diastolic Bp, systolic $\mathrm{Bp}$ and INR. Since P-value $<0.05$, then we conclude that there is sufficient evidence to conclude that there is statistically significant relationship between these variables and INR at the 5\% level (Table 5). Further studies need to done in this field with large number of cohorts and other methodologies involving pharmacy pill count to assess patient adherence.

The findings in this study can help health care providers' interventions in $\mathrm{AF}$ patients that may be at risk for poor adherence to OACs. We identified some risk factors associated with poor adherence, which were either modifiable (i.e. patient education) or non-modifiable (age, chronic illness). Regularly scheduled monitoring and contact with health care providers (e.g. written information or telephone intervention) may improve medication adherence. The continuous evaluation of patients' preference and educational intervention regarding the need for OACs, the risks and benefits associated with OAC therapy, and a medication regimen using the patient information card recommended by European Heart Rhythm Association can improve their knowledge, motivation, and skills for self-management. An interdisciplinary team consisting of clinicians, pharmacists, nurses, should be responsible for the initial and continuous education in AF patients.

There were some limitations of this study as it was conducted in a single referred center with a small sample size. However, the prospective design and the accuracy of data give strength to the results and make the study more representative of the patients with NVAF from the real world in our region.

\section{CONCLUSION AND RECOMMENDATION}

The findings of the current study show the absence of patient education program and regular follow up plan for patients on warfarin in our region, so we recommend the construction of anticoagulation clinic for this group of patients in our health system design given the importance of such clinic in improving the quality control of oral anticoagulants.

\section{REFERENCES}

1. Berisso MZ, Lercari F, Carazza T, Domenicucci S. Epidemiology of atrial fibrillation: European perspective. Clin Epidemiol. 2014;6:213-220.

2. Finkel R, Clark MA. Lippincott's Illustrated Reviews: Pharmacology. 2015;6.

3. Brunton LL, Lazo JS, Parker KL. Goodman \& Gilman's The Pharmacological Basis of Therapeutics. 2011;12.

4. longmore M, Wilkinson I, Tomturmezei. Cheek Ay Cheung oxford hand book of clinical medicine seventh edition. 2014. 
5. Kasper DL, Fauci AS. Harrison Principles of Internal Medicine. 2015.

6. Maxine AP, Stephen JM, Michael WR. Current Medical Diagnosis \& Treatment 2016.

7. Wysowski DK, Nourjah P, Swartz L. Bleeding complications with warfarin use: a prevalent adverse effect resulting in regulatory action. Arch Intern Med. 2007;167:1414-1419.

8. Wallvik J, Själander A, Johansson L, Bjuhr O, Jansson JH. Bleeding complications during warfarin treatment in primary healthcare centres compared with anticoagulation clinics. Scand J Prim Health Care. 2007;25:123-128.

9. Björck F, Renlund H, Lip GYH, Wester P, Svensson PJ, Själander A. Outcomes in a warfarin-treated population with atrial. JAMA Cardiol. 2016.

10. Sjögren V, Grzymala LB, Renlund H. Safety and efficacy of well managed warfarin: a report from the Swedish quality register Auricula. ThrombHaemost. 2015;113:1370-1377.

11. Razouki Z, Ozonoff A, Zhao S, Jasuja GK, Rose AJ. Improving quality measurement for anticoagulation: adding international normalized ratio variability to percent time in therapeutic range. CircCardiovascQual Outcomes. 2014;7:664-669.

12. Ibrahim S, Jespersen J, Poller L. European Action on Anticoagulation. The clinical evaluation of international normalized ratio variability and control in conventional oral anticoagulant administration by use of the variance growth rate. J ThrombHaemost. 2013;11:1540-1546.

13. Rosendaal FR, Cannegieter SC, Van der Meer FJ, Briët E. A method to determine the optimal intensity of oral anticoagulant therapy. ThrombHaemost. 1993;69:236-239.

14. Hart RG, Benavente $O$, Pearce LA. Increased risk of intracranial hemorrhage when aspirin is combined with warfarin: a metaanalysis and hypothesis. Cerebrovasc Dis. 1999;9:215-217.

15. Rothberg MB, Celestin C, Fiore LD, Lawler E, Cook JR. Warfarin plus aspirin after myocardial infarction or the acute coronary syndrome: meta-analysis with estimates of risk and benefit. Ann Intern Med. 2005;143:241-250.

16. Jun M, James MT, Manns BJ. Alberta Kidney Disease Network. The association between kidney function and major bleeding in older adults with atrial fibrillation starting warfarin treatment: population based observational study. BMJ. 2015;350:246.

17. Hart RG, Tonarelli SB, Pearce LA. Avoiding central nervous system bleeding during antithrombotic therapy: recent data and ideas. Stroke. 2005;36:1588-1593.

18. Van Asch CJ, Luitse MJ, Rinkel GJ, Van der Tweel I, Algra A, Klijn CJ. Incidence, case fatality, and functional outcome of intracerebralhaemorrhage over time, according to age, sex, and ethnic origin: a systematic review and meta-analysis. Lancet Neurol. 2010;9:167-176.
19. Kagansky N, Knobler H, Rimon E, Ozer Z, Levy S. Safety of anticoagulation therapy in well-informed older patients. Arch Intern Med. 2004;164:2044-2050.

20. Fiona Newall, Paul Monagle, Linda Johnston. Patient understanding of warfarin therapy: A review of education strategies. Hematology. 2005;10:437-442.

21. Tang EO, Lai CS, Lee KK, Wong RS, Cheng G, Chan TY. Relationship between patients' warfarin knowledge and anticoagulation control. Ann Pharmacother. 2003;37:34-39.

22. James LW, Megan DW, Sonal S. Best strategies for patient education about anticoagulation with warfarin: a systematic review. BMC Health Serv Res. 2008;8:40.

23. Newall F, Monagle P, Johnston L. Patient understanding of warfarin therapy: a review of education strategies. Hematology. 2005; 10:437-442.

24. Davis NJ, Billett HH, Cohen HW, Arnsten JH. Impact of adherence, knowledge, and quality of life on anticoagulation control. Ann Pharmacother. 2005;39:632-636.

25. Zeolla MM, Brodeur MR, Dominelli A, Haines ST, Allie ND. Development and validation of an instrument to determine patient knowledge: the oral anticoagulation knowledge test. Ann Pharmacother. 2006;40:633-638.

26. Stefan VV, Manar AA, Thanh DH, Simon S, Tim F, Jean FC. Educating Orally Anticoagulated Patients in Drug SafetyDtschArztebl Int. 2014;111:607-614.

27. Sweta S, Binaya S, Anjana K, Upasana A, Rashmi S. Evaluation of patients' knowledge on warfarin in outpatient pharmacy of a tertiary care cardiac centerBMC Res Notes. 2015;8:429.

28. Ruxandra J, Sebastian M, Oliviana G, Nic D, Sergiu S, Răzvan R, et al. Predictive factors for obtaining a correct therapeutic range using antivitamin $\mathrm{K}$ anticoagulants: a tertiary center experience of patient adherence to anticoagulant therapy. Patient Preference and Adherence. 2015;9:1271-1278.

29. Wong YM, Quek YN, Tay JC, Chadachan V, Lee HK. Efficacy and safety of a pharmacist-managed inpatient anticoagulation service for warfarin initiation and titrationJClin Pharm Ther. 2011;36:585-591.

30. Verret L, Couturier J, Rozon A, Saudrais JS, St Onge A, Nguyen $A$, et al. Impact of a pharmacist-led warfarin self-management program on quality of life and anticoagulation control: a randomized trial. Indian J Pharm Sci. 2013;75:53-59.

31. Hua TD, Vormfelde SV, Abu AM. Practice nursed-based, individual and video-assisted patient education in oral anticoagulation- protocol of a cluster-randomized controlled trial. BMC FamPract. 2011;12. 